\title{
The German AugUR study: study protocol of a prospective study to investigate chronic diseases in the elderly
}

Klaus Stark', Matthias Olden ${ }^{1}$, Caroline Brand1 1,2,3, Alexander Dietl ${ }^{1,4}$, Martina E. Zimmermann ${ }^{1}$, Sabine C. Schelter ${ }^{1,5}$, Julika Loss ${ }^{6}$, Michael F. Leitzmann ${ }^{6}$, Carsten A. Böger ${ }^{7}$, Andreas Luchner ${ }^{4}$, Florian Kronenberg ${ }^{8}$, Horst Helbig ${ }^{2}$, Bernhard H. F. Weber ${ }^{3}$ and Iris M. Heid ${ }^{1 *}$

\begin{abstract}
Background: The majority of patients suffering from chronic health disabilities is beyond 70 years of age. Typical late-onset chronic diseases include those affecting the heart, the kidney, cancer, and conditions of the eye such as age-related macular degeneration. These diseases disable patients for many years and largely compromise autonomy in daily life. Due to challenges in recruiting the elderly, the collection of population-based epidemiological data as a prerequisite to understand associated risk factors and mechanisms is commonly done in the general population within an age-range of 20 to 70 years.
\end{abstract}

Methods/Design: We establish the German AugUR study (Age-related diseases: understanding genetic and non-genetic influences - a study at the University of Regensburg), a prospective study in the mobile elderly general population in and around Regensburg in eastern Bavaria. In the long term, we aim to recruit 3,000 persons of Caucasian ethnicity with at least 70 years of age via residents' registration offices and conduct 3-year follow-ups.

The study protocol includes a standardized interview regarding social and life-style factors, medication history, quality-of-life, and existing diagnoses of common diseases. The participants undergo medical examinations for ophthalmological, cardiovascular or diabetes-related conditions, and general measurements of body shape and fitness. The program is particularly tailored for the elderly. Biobanking of whole blood, serum, plasma, and urine is conducted and standard laboratory measurements are performed in fresh samples.

Discussion: AugUR is specifically designed as a research platform to host studies of late onset diseases. Consequently, this platform will help (1) to unravel the genetic and non-genetic etiology of disease development and progression, (2) to serve as control group of elderly individuals for comparisons with various patient groups, (3) to derive prevalence and incidence data on chronic diseases, and (4) to provide clinical reference parameters for the elderly mobile general population. This data will foster our understanding of disease mechanisms, which may ultimately help to improve prevention, diagnosis, and therapy for frequent chronic diseases. Here we present the baseline study protocol of AugUR.

Keywords: Mobile elderly population, Cross-sectional study, Cohort study, Etiology of chronic diseases, Diseases of late onset, Study platform, Genetic and non-genetic risk factors

\footnotetext{
* Correspondence: Iris.Heid@klinik.uni-regensburg.de

'Department of Genetic Epidemiology, University Regensburg,

Franz-Josef-Strauss-Allee 11, 93053 Regensburg, Germany

Full list of author information is available at the end of the article
} 


\section{Background}

A major proportion of hospitalized patients is above 70 years of age. This is mainly due to a variety of chronic diseases that tend to occur later in life and disable the elderly patients for many years or even decades. Such diseases include type 2 diabetes [1], cancer [2], cardiovascular complications [3], and eye diseases like age-related macular degeneration (AMD) [4], the leading cause of blindness in the elderly.

Morbidity and disability at high age do not only affect individuals' quality of life, but also impact upon public health care systems. Such challenges will increase given demographic changes towards a growing proportion of persons above 80 years of age, in Europe from currently 4 to $10 \%$ in 2050 [5]. Consequently, the number of patients with late-onset diseases will increase. Public health efforts that help increase life expectancy also need to include measures to avoid disabling diseases.

To understand the etiology of late-onset diseases, it is important to know their genetic architecture. Most diseases have a genetic component with a heritability of $40-70 \%[6,7]$ and numerous genetic loci identified $[8,9]$. The knowledge of the genetic background provides insights to disease mechanisms and will stimulate ideas for new therapeutic options. Genome-wide association studies (GWAS) have been immensely successful in describing the genetic basis for numerous diseases [8]. To increase statistical power and to identify even small genetic effects, such analyses are conducted typically by combining the results of multiple studies in meta-analyses. Previous results from GWAS have usually been obtained by merging studies of diverse designs, often recruited from patient groups with limited assessment of non-genetic risk factors, and lack of follow-up. In order to investigate the combination of genetic and life style factors in relation to disease incidence and progression, large population-based prospective follow-up studies with high quality phenotyping are warranted.

Current large-scale prospective epidemiologic studies often focus on adults less than 70 years of age, such as the German National Cohort [10] or the UK Biobank [11]. This is due to the fact that recruiting elderly individuals is particularly challenging regarding the time and patience required for each step of the study program, including walking from one room to another, un- and re-dressing, or answering questions. A further challenge is the impaired visual, auditory, or cognitive function frequently encountered in elderly individuals, necessitating a study program that is tailored to their specific conditions.

Therefore, we set out to establish a study platform using population-based recruitment of mobile elderly individuals in and around the east Bavarian city of Regensburg. This platform will allow for harboring studies on various late-onset common diseases using cross-sectional, casecontrol, or cohort study designs.

\section{Methods/design}

\section{Main objective and overall design}

The main objective of our prospective study platform is to build a data base that enables the investigation of genetic and non-genetic risk factors as well as biomarkers for late-onset diseases. The AugUR study (Age-related diseases: $u$ nderstanding genetic and non-genetic influences - a study at the University of Regensburg) is a prospective study from the general elderly population in and around the city of Regensburg. The baseline survey includes an in-person interview, biobanking and medical examinations. A follow-up with a second in-person visit after 3 years and subsequent mortality and morbidity follow-ups are planned.

\section{Study population and recruitment}

Our study cohort consists of the mobile elderly population at least 70 years of age. The recruitment area is the city and county of Regensburg, which is a middle-sized Bavarian city with 150,000 inhabitants located in the South-East of Germany with the next bigger cities $>100$ $\mathrm{km}$ away; the study region includes both urban and rural areas with a total of $\sim 330,000$ inhabitants, mostly of Caucasian ethnicity. We are aiming at 3,000 participants during a five year recruitment period from 2013 to 2018 with subsequent follow-ups.

For the baseline survey, we obtain a random sample from the local registries of residence. Selected inhabitants are contacted by a mailed invitation letter giving the choice to answer per phone or via a pre-paid post card stating their phone number. Those that contact the study center in order to raise their unwillingness to participate are asked to complete a short phone interview to assess the reasons for refusal, if possible. These persons are not contacted again. In addition, a random subset of non-responders undergoes a non-compliance interview by phone.

Persons indicating their interest in participating the study are contacted and an appointment is made. There are no a priori exclusion criteria. Invited persons are welcomed at the recruitment center at the University Hospital Regensburg. Informed consent is obtained by trained study staff, and those giving consent are subjected to the study program. Participants are asked for agreement to be re-contacted for follow-ups.

\section{Ethic approval, data protection, and informed consent}

The study protocol, study procedures, and data protection strategy were all approved by the Ethics Committee of the University of Regensburg, Germany (vote 12-101-0258). Written consent is obtained according to the Declaration 
of Helsinki. Person-identifying information is strictly separated from the study results using different computer systems and identifying numbers. Original data are stored in a physically safe place with encrypted backup and access limited to a restricted group of staff to ensure safety and confidentiality. Each participant is specifically asked for consent to be contacted in the future, to allow for genetic analyses, and whether he/she wishes feedback regarding their results from the physical and medical examinations and the standard laboratory panel.

\section{Overview of the questionnaire and the physical and medical examinations}

An in-person standardized interview and physical and medical examinations are conducted by trained staff. The questionnaire includes an assessment of sociodemographic (marital status, education, profession) and life style factors (nutrition, dietary supplements, smoking behavior, alcohol consumption, physical activity), comorbidities, medication use, and quality of life. The physical and medical examinations consist of an ophthalmological and a cardiovascular program, measurement of diabetesrelated parameters, general fitness and anthropometry (Table 1). Biobanking is conducted for aliquoted serum, plasma, blood for DNA and RNA as well as urine (Table 2).

Questionnaire data and documentation of examinations are initially recorded on paper and are subsequently transferred to an electronic case report form (eCRF). We opted against using an ad hoc eCRF during the interview, as we found that interaction with elderly persons requires full eye contact and parallel entering of information into the computer system did not yield a time benefit, but caused a disruption of the interview. For collecting and managing eCRF data, a specialized software tool is employed (Askimed, http://www.askimed.com/). Quality control includes monitoring the entered data by a second independent study assistant.

\section{Ophthalmological examination program Overview}

Interview-based ophthalmological medical history assesses the existence, history and time of onset of major eye diseases (cataract, glaucoma, diabetic retinopathy, AMD, former ocular injury or severe infection, family history of eye diseases) or ophthalmological interventions (eye surgery, intravitreal injections, laser treatment, application of eye drops or other eye-specific medication).

\section{Amsler grid test and visual acuity}

In order to assess irregularities in central vision, an Amsler grid test is conducted according to [12]. Briefly, participants are tested, each eye separately, with a black-onwhite Amsler grid $(10 \times 10 \mathrm{~cm}$ with a $0.5-\mathrm{cm}$ grid $)$ at a reading distance of $30 \mathrm{~cm}$ using their most recent reading glasses if needed and available. Participants are instructed to fixate the black spot in the center. The test is classified as positive when the participant claims to see irregularities in the grid (interruptions in the network of the small squares; lines are not straight and parallel; vibration or waving areas; gray hazed areas).

Visual acuity is the main endpoint for ophthalmological diseases. A rapid and simplified visual acuity test is carried out on a standardized Early Treatment Diabetic Retinopathy Study (ETDRS)-chart for the lines with equivalence values of 20/25 Snellen Equivalent and 20/20 Snellen Equivalent at a distance of $4 \mathrm{~m}$. Study participants use their most recent distance glasses if applicable. When $\geq 60 \%$ letters are read correctly, the visual acuity score is increased by +1 at $20 / 25$ or +2 at $20 / 20$, respectively, for each eye separately. When $<60 \%$ letters of $20 / 25$ equivalence value are read correctly, the visual acuity score per eye is -2 .

\section{Photo stress test}

Dark or white adaptation time, which is the time of full adjustment and reading ability of the eye after darkness or very bright light, respectively, provide a psychophysical assessment of retinal function [13-15]. These parameters are associated with multiple eye diseases and are used as surrogate endpoints in clinical studies [16]. While dark adaptation requires high attention and patience of the study participants, the photo stress test to assess white adaptation can be better applied in a standardized fashion. This strategy is the most appropriate and clinically applicable photo-stress bleaching technique, as high intensity, long-duration bleaching minimizes errors [17].

Briefly, starting with the eye with better visual acuity, the participant's refractive correction (if applicable) is removed and the participant is administered to the macular stop of a direct ophthalmoscope (Heine Beta 200 M2, Heine Optotechnik, Herrsching, Germany). The ophthalmoscope is adjusted to full intensity, projecting directly onto the macula for $30 \mathrm{~s}$. Immediately after bleaching, the time until the participant can read one line less than before in the visual acuity test is measured in seconds with refractive correction (if applicable).

\section{Fundus camera imaging}

Many eye diseases affect the retina. We thus conduct fundus photography using the automatized DRS fundus camera (Digital Retinography System; CenterVue, Padova, Italy) [18]. Pictures are captured for the central and central nasal field of the retina within a $45^{\circ}$ view. The quality of the fundus photographs depends on the pupil size. Therefore, participants' eyes are allowed to adapt in a darkened room for 5 min before photography. Since pupil size is known to be age-dependent [19], it is likely that 
Table 1 Baseline assessment in AugUR

\begin{tabular}{|c|c|c|c|}
\hline Category & Item & Instrument & $\begin{array}{l}\text { Method/apparatus } \\
\text { used }\end{array}$ \\
\hline \multirow[t]{5}{*}{ General factors } & $\begin{array}{l}\text { Age, sex, ethnicity, } \\
\text { martial status }\end{array}$ & Q & Interview \\
\hline & $\begin{array}{l}\text { Education, } \\
\text { profession }\end{array}$ & Q & Interview \\
\hline & Nutritional habits & Q & Interview \\
\hline & $\begin{array}{l}\text { Smoking, alcohol } \\
\text { consumption }\end{array}$ & Q & Interview \\
\hline & Light exposure & Q & Interview \\
\hline Quality of life & $\begin{array}{l}\text { Subjective health } \\
\text { status, general } \\
\text { condition }\end{array}$ & Q & Interview \\
\hline Anthropometry & Height, weight & $P$ & Measuring station \\
\hline \multirow[t]{3}{*}{ and fitness } & $\begin{array}{l}\text { Waist and hip } \\
\text { circumferences }\end{array}$ & $P$ & Measuring tape \\
\hline & Hand grip strength & $P$ & Dynamometer \\
\hline & Physical activity & Q & Interview \\
\hline Medication & $\begin{array}{l}\text { Current medication } \\
\text { intake }\end{array}$ & Q & Interview \\
\hline Ophthalmological & $\begin{array}{l}\text { Eye diseases and } \\
\text { eye injuries }\end{array}$ & $\mathrm{Q} / \mathrm{P}$ & $\begin{array}{l}\text { Interview, DRS, } \\
\text { OCT }\end{array}$ \\
\hline \multirow[t]{2}{*}{ Phenotyping } & Ocular fundus & $P$ & DRS, OCT \\
\hline & Visual acuity & $P$ & ETDRS, Amsler \\
\hline Cardiovascular & $\begin{array}{l}\text { Cardiovascular } \\
\text { diseases }\end{array}$ & Q & Interview \\
\hline \multirow[t]{6}{*}{ Phenotyping } & $\begin{array}{l}\text { Blood pressure, } \\
\text { pulse rate }\end{array}$ & $P$ & Automatic device \\
\hline & Ankle-brachial index & $P$ & Vascular Explorer \\
\hline & $\begin{array}{l}\text { Aortic pulse wave } \\
\text { velocity }\end{array}$ & $P$ & Vascular Explorer \\
\hline & Augmentation index & $P$ & Vascular Explorer \\
\hline & $\begin{array}{l}\text { Left/right ventricular } \\
\text { mass and function }\end{array}$ & $P$ & Echocardiography \\
\hline & $\begin{array}{l}\text { Assessment of heart } \\
\text { valves }\end{array}$ & $P$ & Echocardiography \\
\hline \multirow[t]{3}{*}{ Diabetes } & $\begin{array}{l}\text { History of diabetes, } \\
\text { diabetes medications }\end{array}$ & Q & Interview \\
\hline & $\begin{array}{l}\text { Skin } \\
\text { autofluorescence }\end{array}$ & $P$ & AGE reader \\
\hline & $\begin{array}{l}\text { Serum glucose, } \\
\mathrm{HbA}_{1 c}\end{array}$ & $L$ & $\begin{array}{l}\text { External } \\
\text { laboratory }\end{array}$ \\
\hline \multirow[t]{5}{*}{ Blood parameters } & Blood cell count & L & $\begin{array}{l}\text { External } \\
\text { laboratory }\end{array}$ \\
\hline & $\begin{array}{l}\text { Mean corpuscular } \\
\text { cell volume }\end{array}$ & L & $\begin{array}{l}\text { External } \\
\text { laboratory }\end{array}$ \\
\hline & $\begin{array}{l}\text { Mean corpuscular } \\
\text { hemoglobin content }\end{array}$ & L & $\begin{array}{l}\text { External } \\
\text { laboratory }\end{array}$ \\
\hline & $\begin{array}{l}\text { Mean cellular } \\
\text { hemoglobin } \\
\text { concentration }\end{array}$ & $L$ & $\begin{array}{l}\text { External } \\
\text { laboratory }\end{array}$ \\
\hline & C-reactive protein & L & $\begin{array}{l}\text { External } \\
\text { laboratory }\end{array}$ \\
\hline
\end{tabular}

Table 1 Baseline assessment in AugUR (Continued)

\begin{tabular}{|c|c|c|c|}
\hline & $\begin{array}{l}\mathrm{LDL}-, \mathrm{HDL}-\text {, total } \\
\text { cholesterol, } \\
\text { triglycerides }\end{array}$ & $\mathrm{L}$ & $\begin{array}{l}\text { External } \\
\text { laboratory }\end{array}$ \\
\hline \multirow[t]{3}{*}{ Urine parameters } & $\begin{array}{l}\text { Albumin:Creatinine, } \\
\text { Protein:Creatinine } \\
\text { ratio }\end{array}$ & L & Clinitek \\
\hline & $\begin{array}{l}\text { Glucose, ketone, } \\
\text { nitrite, } \mathrm{pH}\end{array}$ & L & Clinitek \\
\hline & $\begin{array}{l}\text { Erythrocyte and } \\
\text { leukocyte count }\end{array}$ & L & Clinitek \\
\hline \multirow[t]{6}{*}{ Other diseases } & $\begin{array}{l}\text { Respiratory tract } \\
\text { diseases }\end{array}$ & Q & Interview \\
\hline & Kidney diseases & Q & Interview \\
\hline & Arthritic diseases & Q & Interview \\
\hline & Skin diseases & Q & Interview \\
\hline & Liver diseases & Q & Interview \\
\hline & Cancer & Q & Interview \\
\hline
\end{tabular}

$Q$ self-reported information obtained by questionnaire, $L$ laboratory analysis, $P$ physical examination, $H B A_{1 c}$ glycated hemoglobin, $L D L$ low-density lipoprotein, $H D L$ high-density lipoprotein, AGE advanced glycation end products, DRS digital retinography system, OCT optical coherence tomography, ETDRS early treatment diabetic retinopathy study

pupils in our elderly participants are often too small to yield a high-quality photography. Therefore, we apply a mild mydriasis (Mydriaticum UD, pharmaSTULLN, Stulln, Germany), when special consent is given. Participants are explicitly informed about the consequences of mydriasis, such as a ban on driving, and a small risk for acute angle-closure glaucoma ( 1 in 20,000 to 1 in 3,000) $[20,21]$. This risk is minimized by excluding persons from mydriasis that exhibit a flat anterior chamber, as assessed via a portable slit lamp examination (Kowa, Düsseldorf, Germany).

\section{Optical coherence tomography}

Comparable to ultra-sound examinations of inner organs, the optical coherence tomography (OCT) scans the retina,

Table 2 Biobanking in AugUR

\begin{tabular}{llll}
\hline Origin & Fraction & $\begin{array}{l}\text { Number of } \\
\text { aliquots }\end{array}$ & $\begin{array}{l}\text { Storage } \\
\text { conditions }\end{array}$ \\
\hline K3-EDTA & Whole blood & $6+4$ & $-20^{\circ} \mathrm{C} /-80^{\circ} \mathrm{C}$ \\
K3-EDTA & Plasma & $12+2$ & $-80{ }^{\circ} \mathrm{C} /$ Liquid $\mathrm{N}_{2}$ \\
Clot & Serum & $12+2$ & $-80^{\circ} \mathrm{C} /$ Liquid $\mathrm{N}_{2}$ \\
activator & & & \\
PAXgene & RNA supernatant & 2 & Liquid $\mathrm{N}_{2}$ \\
PAXgene & RNA cellular & 1 & Liquid $\mathrm{N}_{2}$ \\
Urine & fraction & & Liquid $\mathrm{N}_{2}$ \\
Urine & Urine supernatant & 1 & $-80{ }^{\circ} \mathrm{C}$ \\
\hline
\end{tabular}


especially the macula and the optic disc using light. We apply confocal scanning laser ophthalmoscopy (CSLO) and spectral domain OCT (SD-OCT) using the SPECTRALIS OCT Plus BluePeak (Heidelberg Engineering $\mathrm{GmbH}$, Heidelberg, Germany). This includes several views of the retina: (i) a set of high-resolution cSLO fundus images including infrared, blue reflectance, BluePeak autofluorescence as well as multicolor mode for each participants' eye in $30^{\circ}(8.7 \mathrm{~mm})$ standard fovea centered view field with 30 averaged frames by Automatic Real-Time (ART), (ii) a set of fovea-centered SD-OCT scans (all in standard TruTrack active eye tracking mode and with quality index as high as possible) including one $30^{\circ}(8.7 \mathrm{~mm})$ horizontal scan averaged with 100 ART, and horizontal raster pattern scans, $20^{\circ} \times 20^{\circ}(5.8 \mathrm{~mm} \times 5.8 \mathrm{~mm})$, consisting of $49 \mathrm{sec}-$ tions, each averaged with 30 ART, and, additionally one $30^{\circ}(8.7 \mathrm{~mm})$ horizontal and vertical line, each averaged with 100 ART in enhanced depth imaging mode, and (iii) a circled SD-OCT scan around the optic disc with 100 ART to assess retinal nerve fiber layers.

SD-OCT scans and cSLO images are analyzed applying the Heidelberg Eye Explorer software (Heidelberg Engineering GmbH, Heidelberg, Germany).

\section{Cardiovascular examinations Overview}

The interview-based medical history assessment includes the existence, history, and time of onset of cardiovascular diseases and interventions. Lipid parameters are measured in fresh blood in non-fasting condition. Fasting before study center visit was unacceptable for our elderly study population. In order to assess subclinical and clinical cardiovascular conditions, we established an indepth phenotyping program including measurement of blood pressure, pulse rate, vascular status, and imaging by a short (for all) and an extended (for a subgroup) cardiac ultrasound protocol as described below.

\section{Blood pressure, pulse and vascular phenotyping}

Blood pressure and pulse rate are measured using an automatic device (Omron M10-IT; Omron Healthcare Co Ltd., Kyoto, Japan) after 5 min of resting time. Blood pressure is measured three times and the average of the second and third measurement is determined. Anklebrachial index, aortic pulse wave velocity and augmentation index are derived from the Vascular Explorer system (Enverdis GmbH medical solutions, Jena, Germany).

\section{Echocardiography}

The echocardiographic measurements are intended to provide established and reliable parameters of the morphology and function of the heart chambers and valves. We use a commercially available ultrasound unit (HP Sonos 5500 with 2-4 MHz probe; Philips,
Eindhoven, The Netherlands) and implement the recommendations of the European Association of Echocardiography for clinical trials [22]. Each measurement is repeated three to ten times according to protocol to reduce random error. The stored tracings are assessed post hoc using analytical software Xcelera R3.2 L1 Version 3.2.1.520 - 2011 (Philips, Eindhoven, The Netherlands). We established a short and an extended protocol.

The short echocardiographic program focuses on left ventricular function and the morphology of the four heart chambers accounting for chamber-specific cardiac remodeling processes [23]. Cardiac morphology including areas and volumes of the four heart chambers determined in the apical four- and two-chamber views as well as left ventricular dimensions assessed by twodimensional guided $\mathrm{M}$-mode in the left parasternal long axis view are recorded [24]. The left ventricular mass is calculated by the Devereux formula [25]. For functional evaluation, left ventricular systolic function is determined by the ejection fraction estimated by the modified Simpson's method [24]. Diastolic function is assessed by pulse wave Doppler measurement of the transmitral flow profile and pulsed tissue Doppler assessment of the diastolic mitral annular velocity as described previously [26] and recommended by the American Society of Echocardiography [27]. This program is performed by a study nurse who was trained at the Cardiology Clinic of the University Hospital Regensburg and has conducted more than 300 echocardiographic examinations before starting to examine without supervision.

For a subgroup of participants, we conduct an extended echocardiographic program additionally assessing right ventricular function and the heart valves performed by an experienced cardiology-trained physician. The following parameters are determined: right ventricular function is estimated by tricuspid annular plane systolic excursion and the Tei-Index calculated by tissue Doppler imaging [28]. For an assessment of the heart valves, transvalvular flow profiles are acquired [29].

\section{Assessment of diabetes-related parameters, anthropometry and general fitness}

Information about previous diagnosis of diabetes and diabetes therapy are obtained at the interview. $\mathrm{HbA}_{1 \mathrm{c}}$ and glucose measurements are conducted in fresh blood. In order to derive a marker for diabetes and cardiovascular risk [30], we assess skin autofluorescence to measure advanced glycation end products (AGE) using the AGE Reader SU (DiagnOptics, Groningen, The Netherlands).

Anthropometric measurements are carried out following the World Health Organization recommendations [31]. Height and weight (using a Seca measuring station 285; Seca, Hamburg, Germany) as well as waist and hip circumference (using a measuring tape) are measured in 
standing position with light clothing to the nearest $0.5 \mathrm{~cm}$ (height, waist and hip circumference) and the nearest $0.1 \mathrm{~kg}$ (weight).

General fitness is assessed using hand grip strength (Jamar Plus + Digital Hand Dynamometer; Patterson Medical, Warrenville, IL, USA). Each hand is tested three times using the right hand first. This test was chosen over other available fitness (e.g. 6 min walk test), since this can be conducted irrespective of visual or motor impairment, which is highly prevalent given at the age range of our participants.

Measurements of AGE, anthropometry, and hand grip strength are performed according to the protocols for the German National Cohort [10].

\section{Other diseases, current and recent medication intake}

Previous diagnoses of other diseases are assessed at the interview. These include liver, kidney, arthritic and skin diseases as well as cancer and diseases of the respiratory tract. Current and recent medication use is assessed using IDOM software [32], directly from the pharmaceutical registration number, if available. Medication use can help pinpoint a multitude of conditions such as hyperlipidemia, hypertension, and diabetes.

We ask all participants for permission to contact their primary physician, their ophthalmologist, and the last hospital they visited. This allows for confirming and extending interview-based information on disease diagnoses. As one of two tertiary care facilities in the recruitment area, and the only one for Ophthalmology and Dermatology, the University Hospital Regensburg is the hospital that best facilitates the gathering of such information.

\section{Biosampling and immediate laboratory analyses}

Collection and procession of biosamples are conducted following standard operation procedures developed for this study based on established methods and recommendations [33]. Deviations from these standard operation procedures (e.g. extended sample handling at room temperature) are recorded and linked with the biosample information. All samples are processed immediately and are kept on dry ice before final storage at the end of the day. Identification, assignment and link to eCRF data for biosamples including 2D-barcoded tubes are managed by self-developed integrated software. For an overview of biosample aliquots and storage see Table 2.

Non-fasting blood samples are drawn in a sitting position after at least five minutes of resting. Mild venous stasis is applied for a maximum duration of one minute. Whole blood is taken using a $21 \mathrm{G}$ multifly needle (Sarstedt, Nümbrecht, Germany) and is transferred into four serum tubes with clot activator, five tubes containing tripotassium ethylenediaminetetraacetate (K3-EDTA) as an anticoagulant (all Sarstedt) and one PAXgene Blood
RNA tube (PreAnalytiX, Hombrechtikon, Switzerland) with a defined order (serum - > K3-EDTA - > PAXgene). For the PAXgene tube, luer (BD Biosciences, Heidelberg, Germany) and membrane adapter (Sarstedt) are applied. K3-EDTA tubes are gently mixed after blood draw for $5 \mathrm{~min}$.

One K3-EDTA and one serum tube is used for immediate analysis of blood parameters in a central laboratory (synlab, Regensburg, Germany). From the other four K3EDTA tubes, a total of four aliquots à $750 \mu \mathrm{l}$ are transferred to 2D-barcoded tubes (ABgene or Matrix, Thermo Scientific, Hudson, NH, USA) for storage at $-80{ }^{\circ} \mathrm{C}$. For subsequent DNA isolation, 6 aliquots à $1.5 \mathrm{ml}$ are frozen at $-20^{\circ} \mathrm{C}$ in $2 \mathrm{ml}$ standard tubes (Sarstedt). The remaining K3-EDTA tubes are immediately centrifuged at 2,000 $\mathrm{g}$ for $15 \mathrm{~min}$ at room temperature to separate plasma from the cellular fraction. Supernatants are transferred to a fresh $15 \mathrm{ml}$ tube (Sarstedt) and mixed carefully by pipetting up and down. Twelve plasma aliquots à $500 \mu \mathrm{l}$ are transferred to 2D-barcoded tubes (Thermo Scientific) for storage at $-80{ }^{\circ} \mathrm{C}$. Additionally, two aliquots à $1.5 \mathrm{ml}$ are stored in sterile $2 \mathrm{ml}$ cryo tubes (Sarstedt) in liquid nitrogen gas phase.

Serum tubes with clot activator are left in upright position for 30 min after blood draw and are centrifuged at 2,000 g for $15 \mathrm{~min}$ at room temperature to separate serum from the cellular fraction as soon as possible. Supernatants from three serum tubes are transferred to a fresh $15 \mathrm{ml}$ tube (Sarstedt) and mixed carefully by pipetting up and down. Twelve serum aliquots à $500 \mu \mathrm{l}$ are transferred to 2D-barcoded tubes (Thermo Scientific) for storage at $-80{ }^{\circ} \mathrm{C}$. Additionally, two samples à $1.5 \mathrm{ml}$ are stored in sterile $2 \mathrm{ml}$ cryo tubes (Sarstedt) in liquid nitrogen gas phase.

The PAXgene RNA tube is mixed ten times by turning after blood draw and is immediately centrifuged at 2,300 $\mathrm{g}$ for $10 \mathrm{~min}$ at $4{ }^{\circ} \mathrm{C}$. From the supernatant, two aliquots with $1 \mathrm{ml}$ each are transferred to sterile $2 \mathrm{ml}$ cryo tubes (Sarstedt). The remaining supernatant is transferred to a fresh $15 \mathrm{ml}$ tube (Sarstedt) without disturbing the pellet. Supernatant $(1 \mathrm{ml})$ is used to resolve the pellet in the PAXgene tube and to transfer it to a sterile $2 \mathrm{ml}$ cryo tube (Sarstedt). PAXgene samples are stored in liquid nitrogen gas phase.

Urine is sampled from midstream into a sterile $100 \mathrm{ml}$ cup with a screw cap (Sarstedt). Within $15 \mathrm{~min}$, two urine monovettes (Sarstedt) are filled and centrifuged at 2,300 g for $10 \mathrm{~min}$ at $4{ }^{\circ} \mathrm{C}$. Afterwards, $1.5 \mathrm{ml}$ supernatant is transferred to a sterile $2 \mathrm{ml}$ cryo tube (Sarstedt) and stored in liquid nitrogen gas phase. The urine in monovettes is stored at $-80^{\circ} \mathrm{C}$. During centrifugation, a Clinitek Microalbumin 9 reagent strip (Siemens Healthcare Diagnostics Inc., Tarrytown, NY, USA) is applied on the remaining urine in the cup for analysis of albumin, blood, creatinine, glucose, ketone, leukocytes, nitrite, protein, and $\mathrm{pH}$. 


\section{Information for study participants after the study program}

Each participant who requests feedback from the results of his/her medical examinations and standard laboratory parameters obtains these in a written letter. If applicable, we suggest that the participant seeks advice from his/her general practitioner. In the case of severe abnormalities in the examinations (i.e., life-threatening and treatable), medical support is sought immediately, which is facilitated by our study center being located directly at the University Hospital Regensburg.

\section{Discussion}

AugUR is a study platform with a focus on the elderly population from the city and county of Regensburg, Germany. It incorporates extensive biobanking, genotyping and a modern study protocol specifically tailored to the conditions of the elderly. Embedded sub-studies and measurements in biosamples using '-omics' techniques will make this platform an important resource for research in the elderly.

What can be gained from in-depth epidemiological data in the elderly? A cross-sectional study with participants starting at 70 years of age is usually enriched with cases with a certain disease, and well-matched healthy controls are available. A longitudinal study design also allows for analyzing risk factors, such as the influence of life style factors on disease development and progression, and the interaction of non-genetic with genetic factors. The longitudinal aspect of a study with elderly participants can provide sufficient numbers of incident cases more quickly than a study with younger participants.

Beyond these major objectives of studying disease etiology, a study in the elderly has further practical usability: It yields prevalence and incidence estimates for late-onset diseases that are important determinants for public health managers. Such estimates require highquality data and cannot be easily transferred across countries due to differences in health care systems, genetic background, climatic conditions, and life style. Additionally, a study in the elderly can also serve as a control group for case-control comparisons, which overcomes many of the usual challenges of control group identification: Control groups in genetic studies are often enriched for other diseases, e.g. by recruiting from hospitals, or are substantially younger or from a different region or even country than the patient group. Finally, reference values of clinical diagnostic parameters in the elderly are often lacking and warranted as most such parameters are evaluated in 'normal' adults, but applied to the patients entering the clinics - which are, mostly, of higher age.

We need to acknowledge a limitation of our study, which arises from the fact that only a certain proportion of invited persons will respond and participate and that the response will depend on health status: since all participants are required to make their appointment by phone and to come to the study center in-person, a certain level of mobility and hearing/cognitive ability is required that is not self-evident in that age range. Therefore, we will recruit from the 'mobile' portion of the general elderly population.

In summary, our population-based cohort study in the elderly is a platform that will help to improve our understanding of late-onset disease mechanisms that may, ultimately, lead to improved prevention, diagnosis, and therapy.

\section{Abbreviations \\ AugUR: Age-related diseases: understanding genetic and non-genetic influ- ences - a study at the University of Regensburg; AMD: Age-related macular degeneration; GWAS: Genome-wide association study; CNV: Choroidal neovascularization; GA: Geographic atrophy; eCRF: Electronic case report form; ETDRS: Early treatment diabetic retinopathy; DRS: Digital retinography system; OCT: Optical coherence tomography; CSLO: Confocal scanning laser ophthalmoscopy; SD-OCT: Spectral-domain optical coherence tomography; ART: Automatic real-time; AGE: Advanced glycation end products; K3- EDTA: tripotassium ethylendiaminetetraacetate.}

\section{Competing interests}

The authors have declared that no competing interests exist.

\section{Authors' contributions}

K.S. participated in designing the study, coordinates the study conduct and drafted the manuscript. M.O., C.B., A.D., M.E.Z. and S.C.S. participated in designing the study. JL, M.F.L., C.A.B., A.L., F.K., H.H. and B.H.F.W. contributed to the initiation of the study. I.M.H. designed and supervises the study, and drafted the manuscript. All authors are involved in the study design, have critically reviewed and finally approved the manuscript.

\section{Acknowledgements}

We gratefully acknowledge the excellent assistance of Denisa Martonová, Sylvia Pfreintner, Laura Reisner, Kerstin Rückl, Sven Schmalfuß, Martina Selaskowski, Josef Simon, and Stephanie Unger. Our special thanks go to Franziska Baotic for creating the AugUR logo.

This study is supported by a grant from the German Federal Ministry of Education and Research (BMBF 01ER1206).

We gratefully acknowledge the supporting contribution from Michael Koller and Carl Rauscher.

\section{Author details}

${ }^{1}$ Department of Genetic Epidemiology, University Regensburg, Franz-Josef-Strauss-Allee 11, 93053 Regensburg, Germany. ${ }^{2}$ Department of Ophthalmology, University Hospital Regensburg, Regensburg, Germany. ${ }^{3}$ Institute of Human Genetics, University Regensburg, Regensburg, Germany. ${ }^{4}$ Department of Internal Medicine II, University Hospital Regensburg, Regensburg, Germany. ${ }^{5}$ Centre for Clinical Studies, University Hospital Regensburg, Regensburg, Germany. ${ }^{6}$ Department of Epidemiology and Preventive Medicine, University Regensburg, Regensburg, Germany. ${ }^{7}$ Department of Nephrology, University Hospital Regensburg, Regensburg, Germany. ${ }^{8}$ Division of Genetic Epidemiology, Medical University of Innsbruck, Innsbruck, Austria.

Received: 25 July 2015 Accepted: 7 October 2015

Published online: 21 October 2015

\section{References}

1. Danaei G, Finucane MM, Lu Y, Singh GM, Cowan MJ, Paciorek CJ, et al. National, regional, and global trends in fasting plasma glucose and diabetes prevalence since 1980: systematic analysis of health examination surveys 
and epidemiological studies with 370 country-years and 2.7 million participants. Lancet. 2011;378(9785):31-40.

2. Bray F, Jemal A, Grey N, Ferlay J, Forman D. Global cancer transitions according to the Human Development Index (2008-2030): a population-based study. Lancet Oncol. 2012;13(8):790-801.

3. Moran AE, Forouzanfar MH, Roth GA, Mensah GA, Ezzati M, Flaxman A, et al. The global burden of ischemic heart disease in 1990 and 2010: the Global Burden of Disease 2010 study. Circulation. 2014;129(14):1493-501.

4. Lim LS, Mitchell P, Seddon JM, Holz FG, Wong TY. Age-related macular degeneration. Lancet. 2012:379(9827):1728-38.

5. Eurostat. http://ec.europa.eu/eurostat/web/population-demographymigration-projections/population-data/database. Accessed 16.01.2015.

6. Visscher PM, Hill WG, Wray NR. Heritability in the genomics era-concepts and misconceptions. Nat Rev Genet. 2008;9(4):255-66.

7. Polderman TJ, Benyamin B, de Leeuw CA, Sullivan PF, van Bochoven $A$ Visscher PM, et al. Meta-analysis of the heritability of human traits based on fifty years of twin studies. Nat Genet. 2015;47(7):702-9.

8. Hindorff LA, Sethupathy P, Junkins HA, Ramos EM, Mehta JP, Collins FS, et al. Potential etiologic and functional implications of genome-wide association loci for human diseases and traits. Proc Natl Acad Sci U S A. 2009:106(23):9362-7.

9. Welter D, MacArthur J, Morales J, Burdett T, Hall P, Junkins H, et al. The NHGRI GWAS Catalog, a curated resource of SNP-trait associations. Nucleic Acids Res. 2014;42(Database issue):D1001-6.

10. German National Cohort Consortium. The German National Cohort: aims, study design and organization. Eur J Epidemiol. 2014;29(5):371-82.

11. Allen N, Sudlow C, Downey P, Peakman T, Danesh J, Elliott P, et al. UK Biobank: Current status and what it means for epidemiology. Health Policy Technol. 2012:1(3):123-6.

12. Amsler M. Earliest symptoms of diseases of the macula. $\mathrm{Br} J$ Ophthalmol. 1953:37(9):521-37.

13. Severin SL, Tour RL, Kershaw RH. Macular function and the photostress test 1. Arch Ophthalmol. 1967;77(1):2-7.

14. Severin SL, Tour RL, Kershaw RH. Macular function and the photostress test 2. Arch Ophthalmol. 1967;77(2):163-7.

15. Dimitrov PN, Robman LD, Varsamidis M, Aung KZ, Makeyeva GA, Guymer $\mathrm{RH}$, et al. Visual function tests as potential biomarkers in age-related macular degeneration. Invest Ophthalmol Vis Sci. 2011;52(13):9457-69.

16. Hammond BR, Fletcher LM, Roos F, Wittwer J, Schalch W. A double-blind, placebo-controlled study on the effects of lutein and zeaxanthin on photostress recovery, glare disability, and chromatic contrast. Invest Ophthalmol Vis Sci. 2014;55(12):8583-9.

17. Margrain TH, Thomson D. Sources of variability in the clinical photostress test. Ophthalmic Physiol Opt. 2002;22(1):61-7.

18. Leitritz MA, Hense HW, Schiefer U, Nagel M, Greiser H, Linseisen J, et al. Development and first results of fast and cost-effective examination methods for an ophthalmological screening within the National Cohort. Klin Monbl Augenheilkd. 2013;230(12):1238-46.

19. Winn B, Whitaker D, Elliott DB, Phillips NJ. Factors affecting light-adapted pupil size in normal human subjects. Invest Ophthalmol Vis Sci. 1994;35(3):1132-7.

20. Wolfs RC, Grobbee DE, Hofman A, de Jong PT. Risk of acute angle-closure glaucoma after diagnostic mydriasis in nonselected subjects: the Rotterdam Study. Invest Ophthalmol Vis Sci. 1997;38(12):2683-7.

21. Pandit RJ, Taylor R. Mydriasis and glaucoma: exploding the myth. A systematic review. Diabet Med. 2000;17(10):693-9.

22. Galderisi M, Henein MY, D'Hooge J, Sicari R, Badano LP, Zamorano JL, et al. Recommendations of the European Association of Echocardiography: how to use echo-Doppler in clinical trials: different modalities for different purposes. Eur J Echocardiogr. 2011;12(5):339-53.

23. Dietl A, Winkel I, Deutzmann R, Schröder J, Hupf J, Riegger G, et al. Interatrial differences of basal molecular set-up and changes in tachycardia-induced heart failure-a proteomic profiling study. Eur J Heart Fail. 2014;16(8):835-45.

24. Lang RM, Bierig M, Devereux RB, Flachskampf FA, Foster E, Pellikka PA, et al. Recommendations for chamber quantification: a report from the American Society of Echocardiography's Guidelines and Standards Committee and the Chamber Quantification Writing Group, developed in conjunction with the European Association of Echocardiography, a branch of the European Society of Cardiology. J Am Soc Echocardiogr. 2005;18(12):1440-63.

25. Devereux RB, Reichek N. Echocardiographic determination of left ventricular mass in man. Anatomic validation of the method. Circulation. 1977;55(4):613-8.
26. Redfield MM, Jacobsen SJ, Burnett Jr JC, Mahoney DW, Bailey KR, Rodeheffer RJ. Burden of systolic and diastolic ventricular dysfunction in the community: appreciating the scope of the heart failure epidemic. JAMA. 2003;289(2):194-202.

27. Nagueh SF, Appleton CP, Gillebert TC, Marino PN, Oh JK, Smiseth OA, et al. Recommendations for the evaluation of left ventricular diastolic function by echocardiography. J Am Soc Echocardiogr. 2009;22(2):107-33.

28. Rudski LG, Lai WW, Afilalo J, Hua L, Handschumacher MD, Chandrasekaran K, et al. Guidelines for the echocardiographic assessment of the right heart in adults: a report from the American Society of Echocardiography endorsed by the European Association of Echocardiography, a registered branch of the European Society of Cardiology, and the Canadian Society of Echocardiography. J Am Soc Echocardiogr. 2010;23(7):685-713.

29. Lancellotti P, Tribouilloy C, Hagendorff A, Popescu BA, Edvardsen T, Pierard $L A$, et al. Recommendations for the echocardiographic assessment of native valvular regurgitation: an executive summary from the European Association of Cardiovascular Imaging. Eur Heart J Cardiovasc Imaging. 2013;14(7):611-44.

30. Lutgers HL, Gerrits EG, Graaff R, Links TP, Sluiter WJ, Gans RO, et al. Skin autofluorescence provides additional information to the UK Prospective Diabetes Study (UKPDS) risk score for the estimation of cardiovascular prognosis in type 2 diabetes mellitus. Diabetologia. 2009;52(5):789-97.

31. World Health Organization. WHO STEPS Surveillance Manual: The WHO Stepwise approach to chronic disease risk factor surveillance. World Health Organization, Geneva. 2005. http://whqlibdoc.who.int/publications/2005/ 9241593830_eng.pdf. Accessed 24.06.2015.

32. Mühlberger N, Behrend C, Stark R, Holle R. Datenbankgestützte Online-Erfassung von Arzneimitteln im Rahmen gesundheitswissenschaftlicher Studien - Erfahrungen mit der IDOM-Software. Informatik, Biometrie und Epidemiologie in Medizin und Biologie. München: Urban \& Fischer; 2003. p. 601-3.

33. Kühn A, Nieters A, Köttgen A, Goek ON, Michels K, Nöthlings U, et al. Feasibility and quality development of biomaterials in the pretest studies of the German National Cohort. Bundesgesundheitsblatt Gesundheitsforschung Gesundheitsschutz. 2014;57(11):1255-63.

\section{Submit your next manuscript to BioMed Central and take full advantage of:}

- Convenient online submission

- Thorough peer review

- No space constraints or color figure charges

- Immediate publication on acceptance

- Inclusion in PubMed, CAS, Scopus and Google Scholar

- Research which is freely available for redistribution

Submit your manuscript at www.biomedcentral.com/submit
C BioMed Central 